\section{Prevalence of chronic obstructive pulmonary disease and associated factors: the PLATINO Study in São Paulo, Brazil}

\author{
Prevalência de doença pulmonar obstrutiva \\ crônica e fatores associados: \\ Estudo PLATINO em São Paulo, Brasil
}

\author{
Ana Maria Baptista Menezes 1 \\ José Roberto Jardim 2 \\ Rogelio Pérez-Padilla 3 \\ Aquiles Camelier 2 \\ Fernanda Rosa ${ }^{2}$ \\ Oliver Nascimento 2 \\ Pedro Curi Hallal 1 \\ PLATINO Team 4
}

\footnotetext{
1 Programa de Pós-graduação em Epidemiologia, Universidade Federal de Pelotas, Pelotas, Brasil.

2 Departamento de Medicina, Universidade Federal de São Paulo, São Paulo, Brasil.

3 Instituto Nacional de Enfermedades Respiratorias, México DF, México.

4 PLATINO Team: Ana Maria Baptista Menezes (Brazil), José Roberto Jardim (Brazil), Rogelio Pérez-Padilla (Mexico), Adriana Muino (Uruguay), Maria Victorina López (Uruguay), Gonzalo Valdivia (Chile), Maria Montes de Oca (Venezuela), Carlos Tálamo (Venezuela).

Correspondence A. M. B. Menezes Departamento de Clínica Médica, Programa de Pós-graduação em Epidemiologia, Universidade Federal de Pelotas. Av. Domingos de Almeida 1146, casa 25, Pelotas, RS 96085-470, Brasil. anamene@terra.com.br
}

\begin{abstract}
Chronic obstructive pulmonary disease (COPD) is now a major public health concern; deaths attributable to COPD in Latin America have increased by $65.0 \%$ in the last decade. This study was aimed at evaluating COPD prevalence and associated factors in adults ( $\geq 40$ years) living in Greater Metropolitan São Paulo, Brazil. The study is part of the Proyecto Latinoamericano de Investigación en Obstrucción Pulmonar (The PLATINO Project), a multi-center survey on COPD burden in Latin America, with São Paulo as the first center where the project has been carried out. A population-based sample was selected in multiple stages. Spirometry tests were performed in each subject pre- and postbronchodilator and COPD was mainly defined as the ratio of forced expiratory volume to forced vital capacity below 70.0\% (fixed ratio definition). Other spirometric criteria were also used for the diagnosis of COPD. COPD prevalence was 15.8\% (95\%CI: 13.5-18.1) using the fixed ratio definition. COPD was positively associated with age and smoking and inversely with body mass index. Utilization of different COPD spirometry criteria resulted in different percentages of COPD, but similar associated factors.
\end{abstract}

Chronic Obstructive Pulmonary Disease; Risk Factors; Tobacco; Pollution; Spirometry

\section{Introduction}

With the recent epidemiological transition in Brazil, chronic diseases, including chronic obstructive pulmonary disease (COPD), now occupy the leading positions in morbidity and mortality in the country. According to government sources 1, one-fourth of all hospitalizations for respiratory problems in adults are due to COPD. Analyzing mortality data, COPD ranks first among causes of mortality due to respiratory diseases in adults (Ministério da Saúde. Informações de Saúde On-line. http://www. datasus.gov.br, accessed on 10/Aug/2004).

COPD is thus an important public health problem, not only because of its high morbidity and mortality, but also because it is a preventable disease in many cases. For example, cessation of smoking - the main risk factor for COPD - could prevent millions of cases. Unfortunately, the natural history of COPD is progressive and irreversible after a certain amount of damage occurs to the lungs, in which case treatment can only relieve the symptoms. It is well known that the rate of lung function loss can be reduced if smoking is stopped, and smoking cessation is the only measure that can improve survival.

COPD is still poorly understood by a large proportion of physicians and unknown to the population at large. Knowledge on COPD must be increased such that the majority of health 
professionals can recognize the disease and treat patients while there is still a chance of improving their quality of life and preventing lung function impairment.

There is considerable discussion about the best diagnostic criteria for this disease. Although there is agreement that spirometry is the main diagnostic key, there is no consensus as to the best spirometric criterion. A fixed ratio of forced expiratory volume in one second $\left(\mathrm{FEV}_{1}\right)$ / forced vital capacity (FVC) below $70.0 \% 1$ can be considered a good indicator for the disease, since it is easy and does not require reference values for each population. However this criterion is quite sensitive and produces a certain number of false positives. On the other hand, the GOLD criterion (Global Initiative for Chronic Obstructive Lung Disease. Global Strategy for the Diagnosis, Management, and Prevention of Chronic Obstructive Pulmonary Disease. http://www.goldcopd.com, accessed on $10 / \mathrm{Aug} / 2004$ ) is very specific and provides a unique opportunity to evaluate severity of COPD. Unfortunately, it depends on reference values, and such information is not always available.

This paper is not intended to discuss the best criterion for diagnosing COPD. Rather, it describes COPD prevalence according to the fixed ratio functional criterion and the variables associated with it.

\section{Materials and methods}

A population-based cross-sectional study was conducted in Greater Metropolitan São Paulo during the first semester of 2003. São Paulo was the first site included in the Proyecto Latinoamericano de Investigación en Obstrucción Pulmonar (PLATINO Project), a multi-center survey on COPD in major cities of Latin America. Details of the multi-center study methodology are described elsewhere 2 . São Paulo is the largest metropolitan area in Brazil, with a population of 17.8 million, located at 23 degrees South, with an altitude of 760m (Demographic and Geographic Data of the World Cities. http:// www.infoplease.com, accessed on 10/Aug/2004).

The sample was selected in multiple stages. First, all census tracts in the city and metropolitan area were listed and sorted by socioeconomic status. Then, 68 tracts were selected following a systematic protocol, which guaranteed stratification by socioeconomic status and tract size proportional probability. In each sampled tract, all households were listed and the total count was updated; the ratio between the expected number of households and the actual count was used to calculate the number of households to be sampled from that tract. On average, 15 households were expected to be selected from each tract, but this number was greater for tracts where the number of households had increased since the previous census, and smaller for tracts where it had declined. Households were then systematically selected from the updated listings. All adults aged 40 years or more living in the selected households were included in the study.

The sample size obtained $(n=963)$ allowed us to estimate a COPD prevalence of $15.0 \%$ with a $2.5 \%$ margin of error. We were also able to detect prevalence ratios of 1.75 or greater with a power greater than $80.0 \%$ and confidence level of $95 \%$ for exposures with frequency between $25.0 \%$ and $75.0 \%$. These calculations considered sample clustering and additional for nonresponse and multivariate analysis.

Each subject was submitted to spirometry before and after bronchodilator use. Although there are several spirometric criteria available to define COPD (Table 1), we opted to use the fixed ratio (FR) criterion, which considers COPD as a ratio of $\mathrm{FEV}_{1} / \mathrm{FVC}$ below $70.0 \%$ 1, independently of reference values for each population. Several symptoms and clinical diagnoses of pulmonary diseases were also investigated.

The questionnaire included sections from the following instruments: American Thoracic Society-Division of Lung Diseases (ATS/DLD) 3 , ECRHS II (European Community Respiratory Survey II. http://ecrhs.org/quests.htm, accessed on 10/Aug/2004), Lung Health Study (Lung Health Study Questionnaire. http://www. bccrc.ca/downloads/ci/lc02_questionnaire.do c, accessed on 10/Aug/2004). A copy of the questionnaire is available upon request. Height was measured with a portable Seca stadiometer (precision $0.1 \mathrm{~cm}$ ), using the Lohman technique 4 . A portable, battery-operated, ultrasound transit-time based spirometer (Easy-One from NDD, Switzerland) was used. Calibration was checked daily. Subjects performed up to 15 forced expiratory maneuvers to obtain three ATS acceptable maneuvers, with FVC and $\mathrm{FEV}_{1}$ reproducible to $150 \mathrm{ml}$. A bronchodilator (salbutamol 200mcg) was then administered and the test was repeated 15 minutes later. All spirometric examinations were carried out with the subject seated, wearing a nose clip and a disposable mouthpiece.

Spirometry quality was evaluated and most tests (over 90.0\%) achieved ATS criteria of quality 5 . The quality control results were fed back to each fieldworker weekly, and the latter were retrained if needed. 
The exclusion criteria for the study were mental disease and institutionalization (less than $3.0 \%$ ). Spirometry was not performed in subjects who reported, in the previous three months, thoracic or abdominal surgery, myocardial infarction, eye surgery (or detached retina), hospitalization for any cardiac problem, current treatment for tuberculosis, or pregnancy. The fieldworker took each subject's pulse before the exam, and those with heart rates over 120 beats/minute were excluded. There were 16 exclusions in this phase of the study.

Analyses used the Stata program taking into account the sampling design with the svy set of commands. Anthropometric data were not entered in the main analyses (multivariate), due to a high likelihood of reverse causality.

Ethical approval was obtained from the Institutional Review Board/Research Ethics Committee of the Escola Paulista de Medicina. The results of spirometric tests were mailed to each subject, and those with abnormal results were offered free consultation at a hospital or rehabilitation center. Written informed consent was obtained from each participant.

\section{Results}

Within the 1,113 households sampled, there were 1,150 individuals eligible for the study; of these, 963 performed spirometry. The overall non-response rate was $15.3 \%$, taking into account both household and individual contact failures and refusals (including refusals only for spirometry). Therefore, analyses of COPD were carried out using 963 data points, although analyses of associated factors used a maximum of 1,000 individuals. Non-respondents were similar to respondents in terms of age and smoking status, but women responded more than men (90.0\% and $83.4 \%$, respectively).

A description of the sample in terms of the demographic and socioeconomic independent variables is presented in Table 1 . As expected, due to the longer life expectancy, there were more women than men in our sample. Mean age was 55.2 years $(S D=11.3)$. Most subjects classified themselves as white, followed by mixed-race and black. Indigenous Brazilians and Asians were rare. Approximately one in six reported a family history (parents, siblings, or children) of COPD, chronic bronchitis, or emphysema. Average schooling was 5.9 years $(\mathrm{SD}=$ 4.9). We also asked about the father's schooling; approximately one-fourth were unable to inform their fathers' level of schooling, while
Table 1

Sample description according to demographic and socioeconomic variables. São Paulo, Brazil, 2003.

\begin{tabular}{|c|c|}
\hline Variable & $\%$ \\
\hline \multicolumn{2}{|c|}{ Gender $(n=1,000)$} \\
\hline Male & 44.2 \\
\hline Female & 55.8 \\
\hline \multicolumn{2}{|c|}{ Age in years $(n=999)$} \\
\hline $40-49$ & 39.0 \\
\hline $50-59$ & 32.0 \\
\hline$\geq 60$ & 29.0 \\
\hline \multicolumn{2}{|c|}{ Skin color/Ethnicity $(n=1,000)$} \\
\hline White & 57.5 \\
\hline Mixed-race & 27.6 \\
\hline Black & 10.4 \\
\hline Indigenous & 2.3 \\
\hline Asian & 2.2 \\
\hline \multicolumn{2}{|c|}{ Family history of COPD, bronchitis, or emphysema ( $n=999$ ) } \\
\hline No & 14.7 \\
\hline Yes & 85.3 \\
\hline \multicolumn{2}{|c|}{ Schooling (years of formal education) $(n=997)$} \\
\hline $0-2$ & 23.4 \\
\hline $3-4$ & 30.9 \\
\hline $5-8$ & 22.7 \\
\hline$\geq 9$ & 23.0 \\
\hline \multicolumn{2}{|c|}{ Father's schooling $(n=1,000)$} \\
\hline None & 46.6 \\
\hline Some & 26.2 \\
\hline Do not know & 27.2 \\
\hline
\end{tabular}

COPD = chronic obstructive pulmonary disease

about one-half reported that their fathers had never attended school.

Table 2 shows the description of the sample in terms of behavioral, anthropometric, and environmental variables. Nearly one-fourth $(24.0 \%)$ were smokers, and an additional third (33.1\%) were former smokers, while $42.9 \%$ had never smoked. Current smokers accounted for $30.2 \%$ of the men and $19.0 \%$ of the women. When $10.0 \%$ of the sample was re-interviewed for quality control, the Kappa statistic for smoking was 0.95 , showing a high degree of repeatability. Lifetime exposure to active smoking was also assessed; $19.0 \%$ of all subjects informed having smoked more than 10 packyears. Prevalence of reported passive smoking in the subject's home in the previous two weeks was $30.1 \%$. 


\section{Table 2}

Sample description according to behavioral, anthropometric, and environmental variables. São Paulo, Brazil, 2003.

\begin{tabular}{|c|c|}
\hline Variable & $\%$ \\
\hline \multicolumn{2}{|l|}{ Smoking status $(\mathrm{n}=999)$} \\
\hline Never smoked & 42.9 \\
\hline Former smoker & 33.1 \\
\hline Current smoker & 24.0 \\
\hline \multicolumn{2}{|l|}{ Lifetime cigarettes smoked $(n=989)$} \\
\hline Never smoked & $43.4^{\star}$ \\
\hline$\leq 1$ pack-years & 16.4 \\
\hline 1.1-10 pack-years & 20.9 \\
\hline$>10$ pack-years & 19.3 \\
\hline \multicolumn{2}{|l|}{ Passive smoking ( $n=998)$} \\
\hline No & 69.9 \\
\hline Yes & 30.1 \\
\hline \multicolumn{2}{|l|}{$\begin{array}{l}\text { Hospital admission due respiratory disease } \\
\text { during childhood }(n=999)\end{array}$} \\
\hline No & 97.1 \\
\hline Yes & 2.9 \\
\hline \multicolumn{2}{|l|}{ Lifetime exposure to dust at workplace $(n=998)$} \\
\hline Never & 43.0 \\
\hline $1-9$ years & 23.9 \\
\hline$\geq 10$ years & 33.1 \\
\hline \multicolumn{2}{|l|}{ Exposure to coal stove for cooking or heating $(n=999)$} \\
\hline No & 85.0 \\
\hline Yes & 15.0 \\
\hline \multicolumn{2}{|l|}{ Exposure to biomass stove for cooking or heating $(n=998)$} \\
\hline No & 50.9 \\
\hline Yes & 49.1 \\
\hline \multicolumn{2}{|l|}{ Waist circumference $(n=996)$} \\
\hline Below cut-off & 54.9 \\
\hline Above cut-off ( $\geq 88 \mathrm{~cm}$ for females or $\geq 102$ for males) & 45.1 \\
\hline \multicolumn{2}{|l|}{ Body mass index $-\mathrm{kg} / \mathrm{m}^{2}(\mathrm{n}=996)$} \\
\hline$<18.5$ & 2.2 \\
\hline $18.5-24.9$ & 35.1 \\
\hline $25.0-29.9$ & 37.3 \\
\hline$\geq 30.0$ & 25.4 \\
\hline
\end{tabular}

* The difference in the number of missing values explains why the percentage of non-smokers is slightly different from the percentage of subjects with no lifetime exposure.
Nearly half of the sample $(45.1 \%)$ presented waist circumference values above the proposed cut-off $(88 \mathrm{~cm}$ for females and $102 \mathrm{~cm}$ for males). Overweight and obese subjects (body mass index: $\mathrm{BMI} \geq 25 \mathrm{~kg} / \mathrm{m}^{2}$ ) comprised almost two-thirds of the sample $(62.7 \%)$. Prevalence was $58.1 \%$ for men and $66.3 \%$ for women. Only $2.9 \%$ of all subjects reported any hospital admission due to respiratory disease during childhood. Exposure to dust in the workplace for 10 years or more was reported by $33.7 \%$ (Table 2 ).

We used several spirometric, symptombased, and clinical diagnostic criteria to estimate COPD prevalence. As expected, these different criteria resulted in a wide range of prevalence. However, variance among spirometry criteria was smaller than the differences in comparison to symptom-based and clinical diagnoses. Table 1 describes all criteria used to estimate COPD prevalence in this study, with respective definitions and prevalence in our sample. The FR criterion resulted in the highest COPD prevalence, while the GOLD criterion resulted in the lowest value.

Four sources of domestic smoke were studied: coal was used for cooking by $14.4 \%$ of all subjects and for heating by $1.7 \%$; the corresponding exposures to biomass (mainly wood) were $47.5 \%$ and $6.4 \%$. Due to the low frequency of exposure to heating fuels, these variables were classified in two groups: exposure to coal and exposure to domestic biomass fuels (Table 3).

Table 4 shows the analysis of demographic and socioeconomic factors associated with COPD. Men were $32.0 \%$ more likely than women to have COPD, but the difference was not significant $(p=0.06)$. Individuals aged 60 or over were three times more likely to have COPD than those aged $40-49$ years. There were no significant associations with skin color. There was no association between family history of bronchitis, emphysema, or COPD and spirometric results. Subjects with up to two years of formal education were 1.5 times more likely to have COPD as those with nine or more years of schooling, but the difference was not significant $(\mathrm{p}=0.14)$.

Table 5 presents the same results for behavioral and environmental factors. Smoking was also strongly associated with COPD. Former smokers had $23.0 \%$ greater risk, and current smokers showed an increase of $104.0 \%$. Hospital admissions due to respiratory disease did not show any association with COPD. Reported exposure to dust in the workplace for 10 years or more was associated with a $36.0 \%$ increase in the risk of COPD, but the difference failed to reach significance $(p=0.08)$. Exposure to coal 
Spirometric, symptom-based, and clinical diagnoses of chronic obstructive pulmonary disease (COPD)

in the PLATINO study with respective definitions and prevalence. São Paulo, Brazil, 2003.

\begin{tabular}{|c|c|c|}
\hline Variable & Definition* & Prevalence \\
\hline \multicolumn{3}{|l|}{ Spirometric criteria } \\
\hline Fixed Ratio & $\begin{array}{l}\text { FEV1/FVC }<70.0 \% \text { (where FEV1 is forced expiratory volume in the first second, } \\
\text { and FVC is forced vital capacity) }\end{array}$ & $15.8 \%$ \\
\hline GOLD II-IV** & FEV1/FVC $<70.0 \%$ and FEV $1<80.0 \%$ of predicted value & $6.0 \%$ \\
\hline ATS $* \star \star$ & FEV1/FVC below 5 th percentile and FEV $1<100.0 \%$ of predicted value & $11.3 \%$ \\
\hline ERS\# & FEV1/FVC $<88.0 \%$ of predicted value for men and $<89.0 \%$ for women & $14.2 \%$ \\
\hline \multicolumn{3}{|l|}{ Symptomatic criteria } \\
\hline Chronic bronchitis & Cough with phlegm for at least 3 months per year in previous 2 years & $3.1 \%$ \\
\hline Emphysema & Breathlessness due to exercise & $36.9 \%$ \\
\hline \multicolumn{3}{|l|}{ Clinical diagnoses } \\
\hline COPD & Reported lifetime diagnosis of COPD & $0.8 \%$ \\
\hline Chronic bronchitis & Reported lifetime diagnosis of chronic bronchitis & $3.9 \%$ \\
\hline Emphysema & Reported lifetime diagnosis of emphysema & $1.2 \%$ \\
\hline
\end{tabular}

* For the analyses of lung function measurements, the NHANES Mexican-American reference values were used 7;

** Global Obstructive Lung Disease (http://www.goldcopd.com);

$\star \star \star$ American Thoracic Society 13;

\# European Respiratory Society 14

smoke in the home also increased the prevalence of COPD by $40.0 \%$, while exposure to domestic biomass smoke was not associated with the outcome.

We also addressed the relationship between spirometric results and anthropometry. Subjects with waist circumference above the proposed cut-off points $(88 \mathrm{~cm}$ for females and $102 \mathrm{~cm}$ for males) showed significantly lower forced expiratory volume $\left(\mathrm{FEV}_{1}\right)(\mathrm{p}<0.001)$ than those with normal waist circumference. While mean $\mathrm{FEV}_{1}$ was $2.73(\mathrm{SD}=0.77$ ) for subjects below the cut-off point, it was 2.37 ( $\mathrm{SD}=0.77$ ) for those above. The same trend was observed for forced vital capacity (FVC), with means of 3.65 $(\mathrm{SD}=0.90)$ and $3.18(\mathrm{SD}=0.94)$ for subjects below and above the cut-off points, respectively $(p<0.001)$. Significantly higher results $(p=0.04)$ for the $\mathrm{FEV}_{1} / \mathrm{FVC}$ ratio were found among subjects above the cut-off point compared with those below. However, when waist circumference was treated as a continuous variable, no significant associations were found with $\mathrm{FEV}_{1}$, $\mathrm{FVC}$, or $\mathrm{FEV}_{1} / \mathrm{FVC}$, indicating possible non-linearity (data not shown in tables).

The association between BMI and COPD was also evaluated. The frequencies of COPD were $50.0 \%, 17.5 \%, 13.9 \%$, and $13.2 \%$ among undernourished, normal-BMI, overweight, and obese, respectively ( $\mathrm{p}<0.001$ ) (data not shown in tables).
All analyses were repeated using the GOLD II-IV definition, and the results were mainly unchanged, except for the fact that $\mathrm{p}$ values tended to be higher due to the lower frequency of COPD using the GOLD definition (data not shown).

\section{Discussion}

The literature is scarce on COPD prevalence and associated factors in Latin America. There are few population-based studies, and most of these have been conducted in selected samples.

COPD is projected to rank fifth in 2020 in terms of worldwide burden of disease 3 . Moreover, COPD is still not recognized as a major public health problem in either developed or developing countries.

The study presented here was an initiative of the Asociación Latinoamericana del Tórax (ALAT) to fill the knowledge gap on this disease in Latin America. It is a multi-center study with five sites (PLATINO Project). São Paulo was chosen as the site in Brazil, and the results shown in this paper relate only to São Paulo.

We wish to emphasize some epidemiological aspects of this study. The survey resulted in a representative sample of a large metropolitan area with a high response rate. For example, according to the DATASUS database from the 
Prevalence of chronic obstructive pulmonary disease (COPD) according to demographic and socioeconomic variables, with respective prevalence ratios (PR), 95.0\% confidence intervals (CI), and significance tests. São Paulo, Brazil, 2003.

\begin{tabular}{|c|c|c|c|c|c|}
\hline \multirow[t]{2}{*}{ Variable } & \multirow[t]{2}{*}{ COPD (\%) } & \multicolumn{2}{|c|}{ Crude analysis } & \multicolumn{2}{|c|}{ Adjusted analysis } \\
\hline & & PR $(95 \% \mathrm{Cl})$ & P-value & PR $(95 \% \mathrm{Cl})$ & $p$-value \\
\hline Gender* & & & $0.09 * \star$ & & $0.06^{\star \star}$ \\
\hline Male & 18.0 & $1.29(0.96-1.73)$ & & $1.32(0.99-1.76)$ & \\
\hline Female & 14.0 & 1.00 & & 1.00 & \\
\hline Age in years ${ }^{\star \star \star}$ & & & $<0.001 \#$ & & $<0.001 \#$ \\
\hline $40-49$ & 8.4 & 1.00 & & 1.00 & \\
\hline $50-59$ & 16.2 & $1.94(1.40-2.69)$ & & $1.94(1.40-2.67)$ & \\
\hline$\geq 60$ & 25.7 & $3.08(2.22-4.27)$ & & $3.11(2.24-4.31)$ & \\
\hline Skin color/Ethnicity\#\# & & & $0.4^{\star \star}$ & & $0.6^{\star \star}$ \\
\hline White & 16.2 & 1.00 & & 1.00 & \\
\hline Mixed-race & 12.8 & $0.79(0.55-1.15)$ & & $0.87(0.61-1.25)$ & \\
\hline Black & 18.6 & $1.15(0.74-1.77)$ & & $1.21(0.79-1.87)$ & \\
\hline Indigenous & 21.7 & $1.34(0.60-3.01)$ & & $1.32(0.60-2.86)$ & \\
\hline Asian & 22.7 & $1.40(0.61-3.23)$ & & $1.35(0.65-2.80)$ & \\
\hline Family history of COPD, bronchitis, or emphysema\#\# & & & $0.9 * \star$ & & $0.9 * \star$ \\
\hline No & 15.7 & 1.00 & & 1.00 & \\
\hline Yes & 16.3 & $1.04(0.65-1.66)$ & & $1.05(0.66-1.66)$ & \\
\hline Schooling (years of formal education)\#\# & & & $0.003 \#$ & & $0.14 \#$ \\
\hline $0-2$ & 22.1 & $2.13(1.28-3.55)$ & & $1.51(0.91-2.50)$ & \\
\hline $3-4$ & 16.3 & $1.58(0.97-2.57)$ & & $1.20(0.73-1.97)$ & \\
\hline $5-8$ & 14.4 & $1.39(0.80-2.43)$ & & $1.27(0.73-2.20)$ & \\
\hline$\geq 9$ & 10.4 & 1.00 & & 1.00 & \\
\hline
\end{tabular}

* Adjustment for age;

$\star \star$ Wald test for heterogeneity;

$\star \star \star$ Adjustment for gender;

\# Wald test for trend;

\#\# Adjustment for gender and age.

Unified National Health System (http:/ / www. datasus.gov.br), $44.1 \%$ of subjects aged 40 years or more living in Greater Metropolitan São Paulo are males; in our sample, the equivalent proportion was $44.2 \%$. Standardization and rigorous quality control procedures ensured that data quality was appropriate (see details on the study's quality control) 2 . Reliance on post-bronchodilator spirometry as the key diagnostic method for COPD and the use of multiple diagnostic indices allowed us to compare this study's results with those from previously published surveys. As the main diagnostic tool for COPD in this study, we had to be certain of the quality control in the spirometry. According to ATS criteria (three acceptable measurements with FVC and $\mathrm{FEV}_{1}$ reproducible to $200 \mathrm{ml}$ ), $87.0 \%$ of the pre- and $95.0 \%$ of the postbronchodilator tests met these recommenda- tions; this shows the good reproducibility of spirometry during this study.

COPD prevalence according to the FR criterion found in this study and compared with another study conducted in southern Brazil 6 shows similar prevalence $(15.8 \%$ and $15.2 \%$, respectively). Although spirometry was performed in a sub-sample in the latter study, the results appear similar and reinforce the specificity of the GOLD criterion as compared to FR, since in both studies the prevalence of COPD by the GOLD criterion was lower. The adoption of FR as the main outcome in the PLATINO Project was due to the absence of reference values for classifying individuals as having COPD in some sites within this multi-center study. For other criteria such as GOLD, it is necessary to compare lung function measurements obtained from the study population with reference val- 
Prevalence of chronic obstructive pulmonary disease (COPD) according to behavioral and environmental variables, with respective prevalence ratios (PR), 95\% confidence intervals (95\% Cl), and significance tests. São Paulo, Brazil, 2003.

\begin{tabular}{|c|c|c|c|c|c|}
\hline \multirow[t]{2}{*}{ Variable } & \multirow[t]{2}{*}{ COPD (\%) } & \multicolumn{2}{|c|}{ Crude analysis } & \multicolumn{2}{|c|}{ Adjusted analysis } \\
\hline & & PR $(95 \% \mathrm{Cl})$ & $p$-value & PR $(95 \% \mathrm{Cl})$ & p-value \\
\hline $\begin{array}{l}\text { Hospital admission for respiratory disease } \\
\text { during childhood* }\end{array}$ & & & $0.8^{\star \star}$ & & $0.7 * \star$ \\
\hline No & 15.9 & 1.00 & & 1.00 & \\
\hline Yes & 13.8 & $0.87(0.34-2.22)$ & & $1.18(0.49-2.89)$ & \\
\hline Lifetime exposure to dust at workplace ${ }^{\star \star \star}$ & & & $0.02 \#$ & & $0.08 \#$ \\
\hline Never & 13.7 & 1.00 & & 1.00 & \\
\hline $1-9$ years & 13.0 & $0.95(0.60-1.49)$ & & $1.04(0.66-1.64)$ & \\
\hline$\geq 10$ years & 20.8 & $1.52(1.09-2.12)$ & & $1.36(0.96-1.93)$ & \\
\hline Exposure to biomass stove for cooking or heating* & & & $0.8^{\star \star}$ & & $0.4^{\star \star}$ \\
\hline No & 15.5 & 1.00 & & 1.00 & \\
\hline Yes & 16.2 & $1.04(0.78-1.40)$ & & $0.88(0.66-1.17)$ & \\
\hline Exposure to coal stove for heating or cooking\#\# & & & $0.03^{\star \star}$ & & $0.08 * \star$ \\
\hline No & 14.7 & 1.00 & & 1.00 & \\
\hline Yes & 22.1 & $1.50(1.05-2.14)$ & & $1.40(0.96-2.03)$ & \\
\hline Smoking status* & & & $0.003 \#$ & & $<0.001 \#$ \\
\hline Never smoked & 12.5 & 1.00 & & 1.00 & \\
\hline Former smoker & 15.5 & $1.24(0.87-1.74)$ & & $1.23(0.88-1.72)$ & \\
\hline Current smoker & 21.9 & $1.76(1.23-2.52)$ & & $2.04(1.41-2.95)$ & \\
\hline
\end{tabular}

* Adjustment for gender, age, schooling, lifetime exposure to dust at workplace, and exposure to coal stove for heating or cooking;

$\star *$ Wald test for heterogeneity;

$\star \star \star$ Adjustment for gender, age, schooling, and exposure to coal stove for heating or cooking;

\# Wald test for trend;

\#\# Adjustment for gender, age, schooling, and lifetime exposure to dust at workplace.

ues from another population or from the same population. Some countries in Latin America lack their own reference curves, and the project thus used the NHANES reference values 7 .

COPD prevalence in São Paulo was similar to that found by Celli et al. 1 (16.0\%) using the FR criterion for analysis of NHANES data (individuals $>30$ years). Review of the literature shows a wide variability in COPD prevalence according to different diagnostic criteria. This has been described by other authors $1,8,9$, emphasizing how much such criteria can affect international prevalence comparisons.

When the PLATINO Project was designed, another multi-center survey was planned in countries outside of Latin America (BOLD Project). Investigators from the two projects decided to use the same methodology, thus allowing future comparisons on prevalence and factors associated with COPD among several countries.

COPD can be under-diagnosed by physicians, with this range varying from $0.8 \%$ for
COPD to $1.2 \%$ for emphysema and $3.9 \%$ for chronic bronchitis. If physicians fail to recognize this disease, patients cannot be treated, nor can the disease be prevented. It is urgent to increase COPD awareness among physicians in order to help thousands of people who suffer from this disease.

Regarding factors associated with COPD, it is well known that the main risk factor is smoking. Despite major efforts in Brazil to reduce smoking, according to our study nearly onefourth of the adult population in São Paulo are current smokers and $33.1 \%$ are former smokers. Another worrisome finding is that more than half of this Brazilian sample are overweight or obese. Using our data on smoking prevalence $(23.9 \%)$ and the adjusted relative risk for COPD among smokers (2.04 for the FR criterion and 2.57 for GOLD II-IV), it was possible to quantify the etiological fraction of smoking on COPD prevalence using the following formula: 

exposure frequency $\mathrm{x}$
etiological fraction $=\frac{(\text { relative risk }-1)}{1+\text { exposure frequency } \mathrm{x}}$
(relative risk - 1)

Using this formula, the attributable fraction of current smoking was $17.9 \%$ according to the FR criterion and $26.2 \%$ with GOLD II-IV. Therefore, smoking control would prevent one out of four to five COPD cases.

Dust exposure at the workplace was related to increased risk of COPD in the crude analysis, but the result did not remain significant after adjusting for gender, age, schooling, and coal exposure. Although non-significant, the adjusted prevalence ratio of 1.36 cannot be ignored in terms of public health. The same was true for coal exposure, which showed a crude prevalence ratio of $1.50(\mathrm{p}=0.03)$, but decreased to $1.40(\mathrm{p}=0.08)$ after adjustment for gender, age, schooling, and dust exposure at the workplace. The negative relationship between COPD and BMI is consistent with the literature 10,11 .

\section{Resumo}

A doença pulmonar obstrutiva crônica (DPOC) é hoje um grande desafio para a saúde pública; as mortes atribuídas a DPOC na América Latina aumentaram 65,0\% na última década. Avaliou-se a prevalência de DPOC e fatores associados em uma população adulta ( $\geq 40$ anos) da grande área metropolitana de São Paulo, Brasil. Esse estudo faz parte do Proyecto Latinoamericano de Investigación en Obstrucción Pulmonar (Projeto PLATINO), um estudo multicêntrico sobre DPOC em grandes cidades da América Latina, tendo sido São Paulo o primeiro centro onde o projeto se realizou. O estudo foi transversal de base populacional e amostragem em múltiplos estágios. Os indivíduos realizaram espirometria, e DPOC foi basicamente definida como a razão entre o volume expiratório forçado em um segundo (VEF1) e a capacidade vital forçada (CVF) abaixo de 70,0\% (relação fixa). Outros critérios espirométricos foram também utilizados para o diagnóstico de DPOC. A prevalência de DPOC foi de 15,8\% (IC95\%: 13,5-18,1) usando-se o critério mencionado acima. DPOC associou-se positivamente com idade e tabagismo e inversamente com o índice de massa corporal. $O$ uso de diferentes critérios espirométricos acarretou mudanças na freqüência de DPOC, mas não nos fatores associados.

Doença Pulmonar Obstrutiva Crônica; Fatores de Risco; Tabaco; Poluição; Espirometria
Two possible limitations of our study should be noted. The first is that some subjects diagnosed as COPD may be asthmatics. Even using post-bronchodilator $\mathrm{FEV}_{1} / \mathrm{FVC}<70.0 \%$, it is impossible to rule out some misclassification. The second limitation is that sample size calculations for analysis of associated factors were initially carried out in order to use the pooled database (using all sites in the multicenter study). Thus, some relevant associations were not detected as significant in this study, such as male gender, coal exposure, and lifetime dust exposure at the workplace, possibly due to the sample size.

To the best of our knowledge, this is the first Brazilian population-based study on COPD prevalence and associated factors based on spirometric results, including over 800 individuals. By showing a strong positive association between COPD and age, our data reinforce the need for closer attention to this health problem, since the Brazilian elderly population is growing 12, and COPD may be one of the leading causes of morbidity and mortality among these subjects in the near future.

\section{Contributors}

A. M. B. Menezes contributed to drafting the article. J. R. Jardim conducted the study in São Paulo and made comments and suggestions on the draft. R. PérezPadilla contributed to drafting and discussing the article. A. Camelier, F. Rosa, and O. Nascimento supervised the spirometry tests. P. C. Hallal conducted the statistical analysis and contributed to the draft. 


\section{References}

1. Celli BR, Halbert RJ, Igbal A, Schau B. Population impact of different definitions of airway obstruction. Eur Resp J 2003; 22:268-73.

2. Menezes AMB, Victora CG, Pérez-Padilla R. The Platino project: methodology of a multicenter prevalence survey of chronic obstructive pulmonary disease in major Latin American cities. BMC Med Res Methodol 2004; 4:15.

3. Ferris BG. Epidemiology standardization project (American Thoracic Society). Am Rev Respir Dis 1978; 118(6 Pt2):1-120.

4. Lohman TG, Roche AF, Martorell R, editors. Anthropometric Standardization Reference Manual. Champaign: Human Kinetics Books; 1988.

5. American Thoracic Society. Standardization of spirometry. 1994 update. Am J Respir Crit Care Med 1995; 152:1107-36.

6. Menezes AM, Macedo SC, Gigante DP, Dias-daCosta J, Olinto MT, Fiss E, et al. Prevalence and risk factors for chronic obstructive pulmonary disease according to symptoms and spirometry. COPD: Journal of Chronic Obstructive Pulmonary Disease 2004; 1:173-9.

7. Hankinson JL, Odencrantz JR, Fedan KB. Spirometric reference values from a sample of the general US population. Am J Respir Crit Care Med 1999; 159:179-87.

8. Renwick DS, Connoly MJ. Prevalence and treatment of chronic airways obstruction in adults over the age of 45 . Thorax 1996; 51:164-8.
9. Petty TL. Scope of the COPD problem in North America. Chest 2000; 117:326-31.

10. Soler JJ, Sanchez L, Roman P, Martinez MA, Perpina M. Prevalence of malnutrition in outpatients with stable chronic obstructive pulmonary disease. Arch Bronconeumol 2004; 4:250-8.

11. Cochrane WJ, Afolabi OA. Investigation into the nutritional status, dietary intake and smoking habits of patients with chronic obstructive pulmonary disease. J Hum Nutr Diet 2004; 17:3-11.

12. Instituto Brasileiro de Geografia e Estatística. Indicadores sociais 2003. Rio de Janeiro: Instituto Brasileiro de Geografia e Estatística; 2004.

13. American Thoracic Society. Standards for the diagnosis and care of patients with chronic obstructive pulmonary disease. Am J Resp Crit Care Med 1995; 152:S77-121.

14. Quanjer PH, Tammeling GJ, Cotes JE, Pedersen OF, Peslin R, Yernault JC. Lung volumes and forced ventilatory flows. Report Working Party Standardization of Lung Function Tests, European Community for Steel and Coal. Eur Respir J Suppl 1993; 16:5-40.

Submitted on $10 /$ Sep/2004

Final version resubmitted on $14 / \mathrm{Feb} / 2005$

Approved on 25/Feb/2005 